\title{
Ambivalente Deutungen des Virus in Facebook-Communities
}

\author{
Guido Murillo Vélez
}

Als am 14. Februar 2020 laut der BBC die erste an Covid-19 erkrankte Person aus Madrid nach Ecuador kam, übertrug der Bayerische Rundfunk live die Fastnacht in Franken. Das Virus schien an jenem Valentinstag in den Augen vieler Menschen weit weg zu sein. Einen Monat später sah die Situation anders aus: Weltweit wurden Ausgangsbeschränkungen erlassen. Infektions- und Todeszahlen schnellten in die Höhe. Bilder von nächtlichen Leichentransporten aus Bergamo oder von auf Gehwegen zurückgelassenen Verstorbenen aus Guayaquil (Ecuador) machten den Ernst der Lage deutlich sichtbar. Ich intensivierte den Kontakt zu meiner Familie in Ecuador und beschäftigte mich verstärkt mit Nachrichtensendungen, Zeitungsartikeln und Beiträgen in den sozialen Medien aus meiner Heimat.

Kurz nach Ostern 2020 tauchte in den sozialen Netzwerken in Ecuador der Cartoon auf, der im Zentrum dieses Beitrags steht (Abb. 4).

An einem Globus sitzend, stehend oder schwebend, mit dem All als Hintergrund und mit lächelnden Gesichtern unterhalten sich Gott und Satan. Die Botschaft scheint einfach: Gott und die Kirche siegen; der Erzfeind muss sich geschlagen geben. Wer zuletzt lacht, lacht am besten. Bei näherer Betrachtung gewinnt aber diese Nebeneinanderstellung gegensätzlicher Figuren an Kontur. Eine verdichtende und mehrschichtige Aussagekraft des Bildes wird deutlich.

Von einer Unterhaltung unter Freunden zum Cartoon über Erzfeinde

Die Zeichnung stammt aus der Feder von Otto Meza, einem Karikaturisten aus El Salvador, der für die digitale Zeitung El Faro arbeitet. In einem Interview bei El Metropolitano Digital vom 14. Oktober 2018 hat sich Meza als einen schlechten Atheisten und einen schlechten Christen bezeichnet.

Zum hier reproduzierten Cartoon hat er in einer persönlichen Mitteilung vom 10. Juli 2020 via Facebook erklärt, dass die Zeichnung auf einer Unterhaltung zwischen zwei Freunden basiere. Er habe dieses Gespräch dann zeichnerisch umgedeutet. Die Zeichnung gründet also auf einem alltäglichen Gespräch zwischen zwei Kollegen im Kontext der Pandemie in 


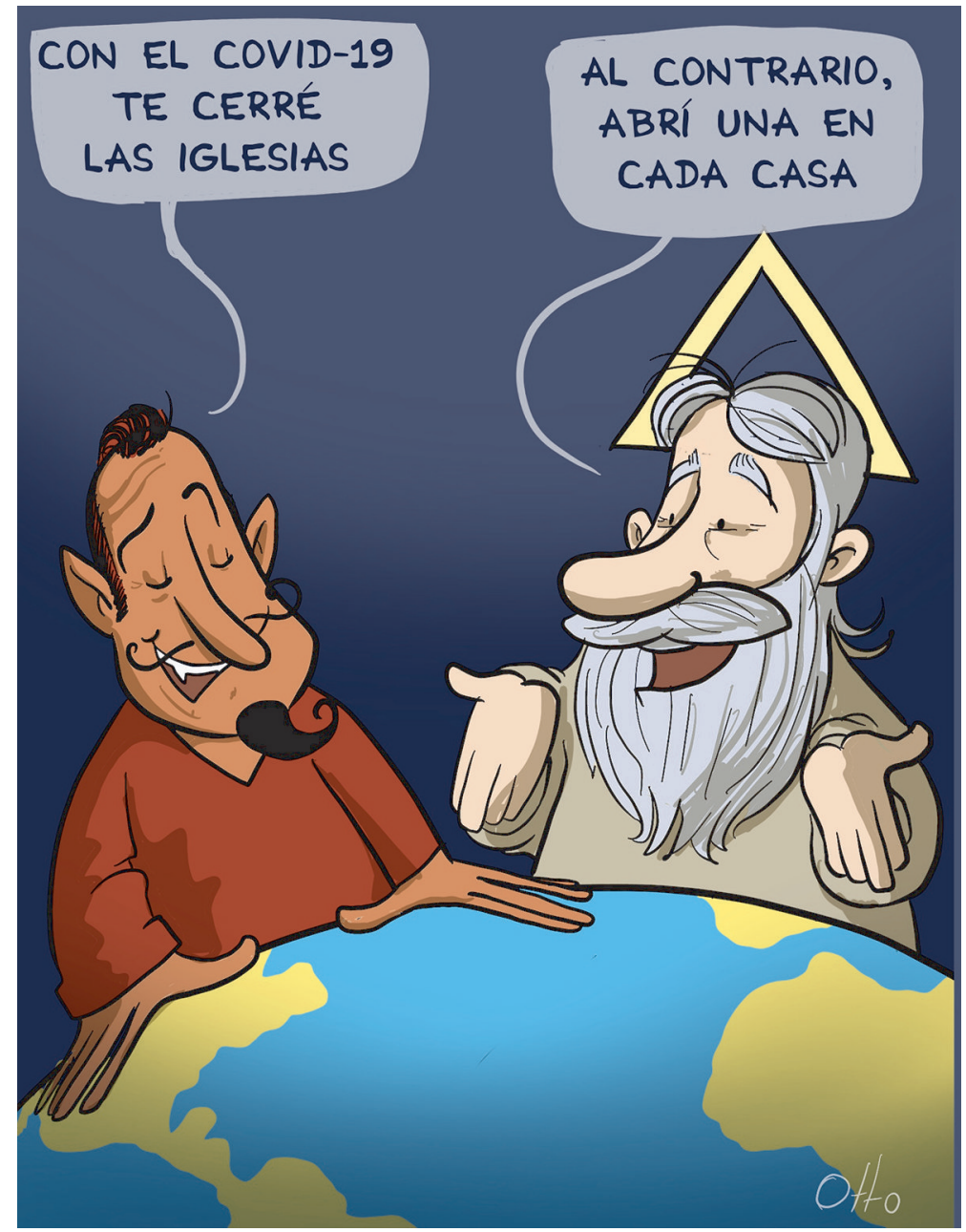

Abb. 4: Cartoon des Künstlers Otto Meza.

Satan: «Mit Covid-19 habe ich dir die Kirchen geschlossen.»

Gott: «Im Gegenteil. Ich habe eine in jedem Haus geöffnet.»

El Salvador. Meza hat daraus einen Cartoon «über Gott und die Welt» gestaltet.

Der Cartoon spielt mit den gegensätzlichen körperlichen Merkmalen und Symbolen, mit denen die transzendenten Protagonisten dargestellt werden. Auf der rechten Seite ist Gott mit einem Dreieck hinter dem Kopf 
gezeichnet. Dieses Symbol, das in der christlichen Ikonographie verankert ist, verweist auf die Dreieinigkeit. Die Figur kann also als Gott Vater oder als trinitarischer Gott gedeutet werden. Ihre Hände berühren die Weltkugel nicht. Ihre auf die Erde verweisende Haltung spiegelt zwar den antwortenden Charakter seiner Aussage, lässt aber zugleich einen Interpretationsspielraum: Wie verhält sich Corona zu Gottes Allmacht? Ist das Virus sein Instrument? Wäscht er seine Hände in Unschuld?

Auf der linken Seite steht der Teufel. Er ist jünger dargestellt als Gott, was im hispano-amerikanischen Kontext klar als Ironie zu verstehen ist. "Más sabe el diablo por viejo, que por diablo» lautet ein verbreiteter Spruch, der Teufel wisse mehr, weil er alt, nicht, weil er der Teufel sei. Im Cartoon erscheint er jedoch jünger als Gott und muss sich am Ende dem Allwissenden unterwerfen. Die Hände des Höllenfürsten strecken sich in besitzergreifender Haltung über den Globus aus und verstärken auf diese Weise die Botschaft, dass Corona sein Instrument ist. Auffällig ist ebenso, dass bei Satan nichts auf ein gemeinschaftliches «Wir» hinweist. Der Teufel hat mit dem Virus die Kirchen geschlossen. Und er verschließt sich selbst gegenüber seinem Gesprächspartner, indem er seine Augen zumacht und den Blickkontakt mit seinem Gegenüber vermeidet.

Die Zeichnung inszeniert vielfältige Kontraste zwischen den himmlischen Figuren in den Farben, in der Haltung, der Gestik und der Positionierung; gemeinsam haben die zwei Antagonisten nur das Lachen. Die Spannung des Cartoons liegt in der offenen Frage, wer sich während und am Ende der Pandemie als Sieger erweisen wird.

\section{Eine Kettenreaktion der Umdeutungen}

Sehr schnell fand der Cartoon über verschiedene Netzwerke den Weg in die Öffentlichkeit. Er wurde in verschiedenen Ländern Lateinamerikas und später auch in lateinamerikanischen Gemeinschaften weltweit - verbreitet. Die rasche Ausbreitung wurde durch die lockere Haltung des Künstlers gegenüber seinem Werk ermöglicht.

Wir verfolgen die Vervielfältigung der Zeichnung an drei exemplarisch ausgewählten Facebook-Posts, die dem ursprünglichen Cartoon zeitnah folgten. 


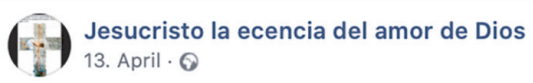

¿No saben que ustedes son templo de Dios y que el Espíritu de Dios habita en ustedes? porque el templo de Dios es sagrado, y ustedes son ese templo.

1 Corintios 3:16-17 NVI

1co.3.16-17.NVI

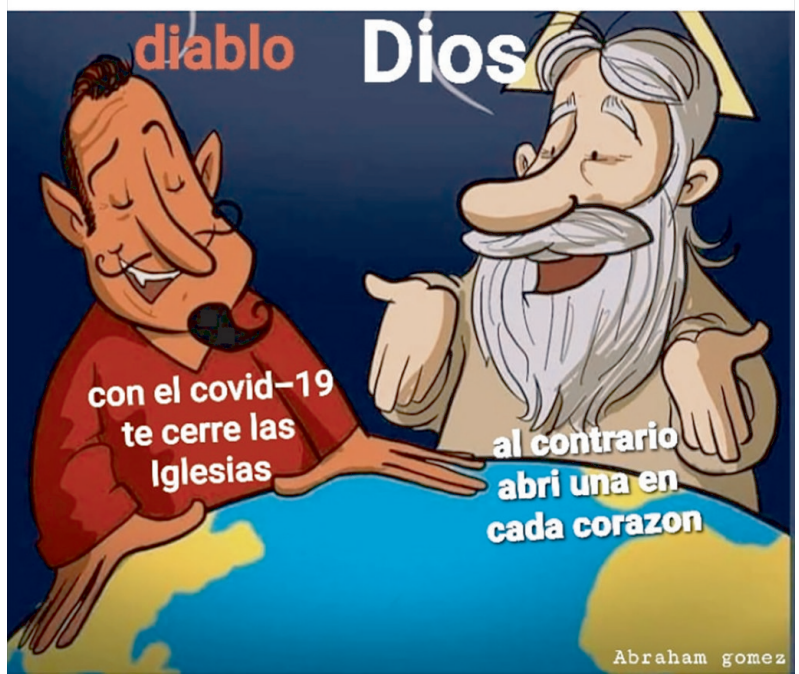

(1) 16

5 Mal geteilt

$\Rightarrow$ Teilen

Abb. 5: Facebook-Account von Jesucristo la ecencia del amor de Dios. «Wisst ihr nicht, dass ihr Gottes Tempel seid und dass der Geist Gottes in euch wohnt? Denn der Tempel Gottes ist heilig, und ihr seid dieser Tempel. (1. Korinther 3,16-17)»

Im Post einer lateinamerikanischen, evangelikalen Gemeinde in Houston gibt es drei interessante Veränderungen des Bildes (Abb. 5): Die Akteure werden durch die hinzugefügte Inschrift hierarchisiert: "Gott» ist groß-, «teufel» kleingeschrieben. Das Bild wurde außerdem oben abgeschnitten und der Dialog nach unten versetzt. Die wichtigste Änderung, die mit dem Zitat aus dem ersten Korintherbrief begründet wird, ist aber die Anpassung der Rede Gottes: Das Haus wird durch das Herz ersetzt. Damit wird die Verinnerlichung der Botschaft betont, da Gott nun sagt: «Im Gegenteil. Ich habe eine in jedem Herzen geöffnet». 
Sociedad Humanista HMS Beagle

13. April . $\odot$

Nos encantan los autogoles. Este meme, regado por los grupos de WhatsApp como la obra más hermosa del bipolar, viene siendo uno de los mejores autogoles de la temporada Covid 2020. Desde que salgamos de esta hay que comenzar las gestiones para eliminar facilidades fiscales y cualquier tipo de privilegio que actualmente se le da a iglesias que, queda claro, están de más, en vista de que cada creyente tiene la suya en su propia casa, que es como debe de ser. Así que apoyamos al $100 \%$ esta iniciativa emanada de los propios creyentes. Cuenten con nosotros en esta.

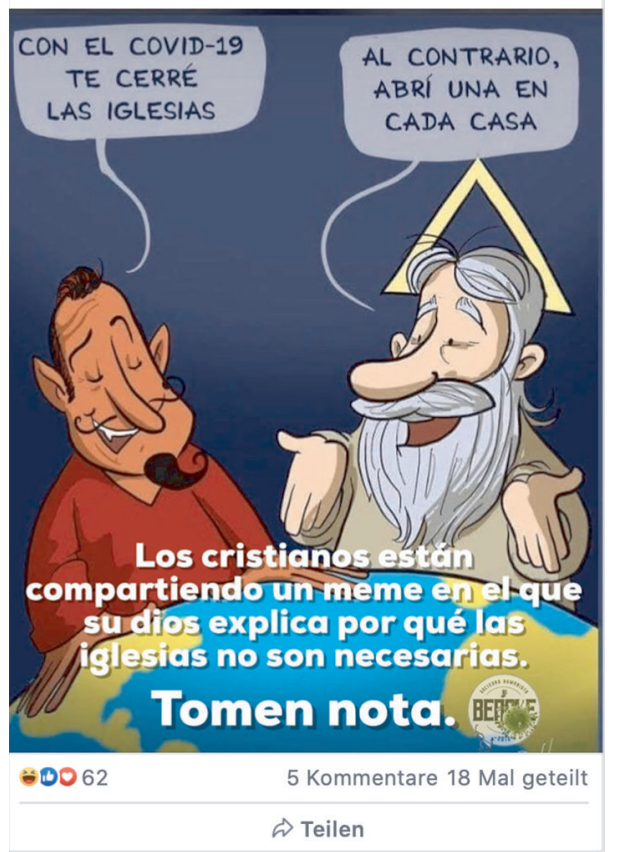

Abb. 6: Facebook-Account von Sociedad Humanista HMS Beagle

Bildunterschrift: «Die Christen teilen gerade ein Meme, auf dem ihr Gott erklärt, warum die Kirchen nicht notwendig sind. Nehmen Sie Notiz davon.»

In Abb. 6 wird die Botschaft in eine ganz andere Richtung verändert. Diese Publikation einer atheistischen Gruppierung aus der Dominikanischen Republik ist aus mehreren Gründen bemerkenswert. Im einleitenden Text wird auf der einen Seite bestätigt, dass die Zeichnung den Weg von der privaten in die öffentliche Sphäre gefunden hat und schon am 13. April 
2020 auf WhatsApp viral gegangen ist. Auf der anderen Seite wird die Botschaft umgewertet und satirisch als «uno de los mejores autogoles de la temporada Covid 2020", eines der besten Eigentore der Covid-Saison 2020, dargestellt. Demnach sei eine Aufgabe der Gesellschaft nach der Pandemie, alle Bevorzugungen und steuerlichen Privilegien der Kirchen abzuschaffen, denn alle Gläubigen könnten ja eine Kirche bei sich zu Hause haben.

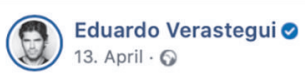

Convierte tu casa en casa de oración A. \#Pazybien ¡Dios los bendiga familia!

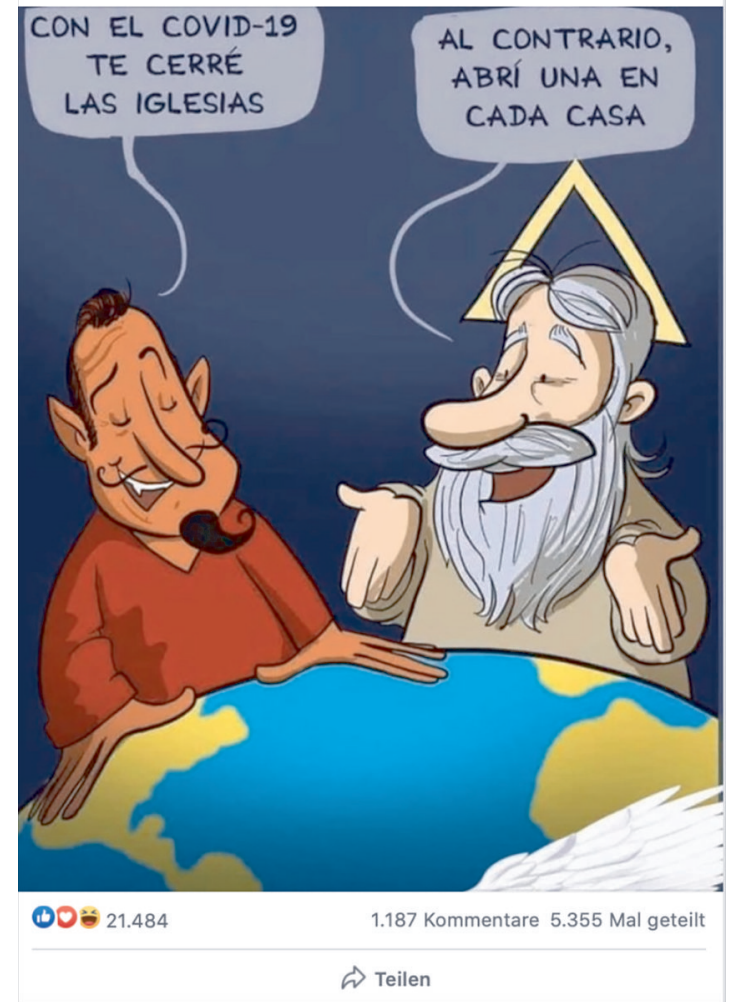

Abb. 7: Facebook-Account von Eduardo Verastegui «Verwandle dein Haus in ein Gebetshaus. \#FriedeundHeil Gott segne Euch, Familie!» 
Abb. 7 zeigt einen Post des mexikanischen Schauspielers, Models, Sängers, Filmproduzenten und politisch tätigen Katholiken Eduardo Verastegui, der Ende Juli 2020 1'559'445 Follower hatte. Hier wird der Cartoon mit minimalen Veränderungen (beispielsweise mit den weißen Flügeln im Vordergrund) übernommen und in den Kontext einer religiösen Praxis gestellt: Verastegui ruft mit dieser Karikatur zum Gebet auf. Diesen Aufruf verbindet er über Hashtags mit den Themenbereichen Frieden und Heil, Gottes Segen und Familie. Somit wird hier das Haus mit der Idee der Familie gekoppelt: Im Kreis der Eigenen zu beten, sei die Grundlage von Frieden und Wohlergehen, was wiederum auf die franziskanische Formel pax et bonum verweist. Verasteguis Fans antworten auf diesen Aufruf und laden Fotos von ihren privaten Altären und Gebetsnischen hoch.

Diese Abbildungsreihe macht die Dynamik von Rezeption und Neuinterpretation sichtbar. In Abb. 5 wird die religiöse Botschaft des ursprünglichen Cartoons verinnerlicht, in Abb. 6 atheistisch umgewertet. Abb. 7 postuliert eine Verbindung zwischen privater oder familiärer und gemeinschaftlicher Religion und startet einen Aufruf zum Gebet, auf den verschiedene Menschen reagieren. Interaktionen lassen sich auf Facebook gut rekonstruieren, weil das soziale Netzwerk so strukturiert ist, dass ein Bild nicht nur publiziert, sondern auch verarbeitet und mit Text und/oder Zeichen (wie Emojis) erweitert werden kann.

\section{Ende gut, alles gut?}

Die Geschichte der Karikatur von Otto Meza zeigt die Komplexität der (medialen) Wirklichkeit auf. Was mit einem alltäglichen Gespräch zwischen zwei Freunden begann, ging durch verschiedene Netzwerke viral und wurde weiterentfaltet und neuinterpretiert. Der ursprüngliche Cartoon generiert ein mannigfaltiges Netzwerk an unterschiedlichen Rezeptions- und Reproduktionsprozessen.

Ilan Danjoux, der politische Cartoons wissenschaftlich untersucht, hebt in seinem Artikel Don't Judge a Cartoon by Its Image von 2013 hervor, wie diese Zeichnungen vielfältige Bedeutungen und Formen verdichten können. Nach ihm besteht das Hauptmerkmal eines Cartoons in seinem offenen und vorwegnehmenden Charakter. Ein Cartoon basiert auf einem aktuellen Ereignis, überlässt jedoch seine Interpretation der Fantasie und der Empfindung der unterschiedlichen Betrachtenden, die sich mit einer bestimmten Begebenheit auseinandersetzen. Deshalb operieren diese Illustrationen zeitgleich als Gegenwartsdeutungen - denn sie werden in der Regel 
in zeitlicher Nähe zu einem bestimmten Ereignis produziert - und als $\mathrm{Zu}$ kunftsbestimmungen.

Die Untersuchung dieser Art von Medien ist besonders aufschlussreich für die Erforschung von Religion, weil sie einen Einblick in die Art und Weise ermöglicht, wie Religion heutzutage gestaltet wird. Zeichnungen wie jene, die hier im Mittelpunkt stehen, sagen viel über die diversen, das Leben formenden Vorstellungen aus. Zu diesen gehört ganz besonders der Teufel als Inbegriff des Bösen. Diese Gestalt beschäftigt Menschen unterschiedlicher Denkrichtungen seit Jahrtausenden.

Auch Otto Mezas Zeichnung spiegelt diese Dramatik zwischen dem Menschen, der Erfahrung und der Berechenbarkeit der Welt wider. Obwohl der Cartoon Corona auf den ersten Blick dem Teufel zuschreibt, kann das Virus durch das Stilmittel der Ellipse auch Gott zugerechnet werden, als ob er sagte: «Im Gegenteil. Mit Covid-19 habe ich eine Kirche in jedem Haus geöffnet». Ob die Pandemie Druckmittel des Teufels oder Gottes Gnade sei, lässt die Zeichnung offen.

In diesem Sinne verrät der Cartoon eine Bewältigungsstrategie im Umgang mit der Pandemie in Lateinamerika, die darin besteht, Corona als schwierige Situation und gleichzeitig als Chance anzusehen. Was der Einzelne daraus macht, ist ihm überlassen. Er kann in seinem Herzen oder seinem eigenen Haus eine Kirche errichten oder sich darauf vorbereiten, ungerechte Strukturen, in die die Kirchen verwickelt sind, abzuschaffen.

\section{Literatur}

Danjoux, Ilan, 2015, Don't Judge a Cartoon by Its Image, in: Yanow, Dvora/ Schwartz-Shea, Peregrine (Hg.), Interpretation and Method. Empirical Research Methods and the Interpretive Turn, London: Routledge, 353-367.

Leiva, Santiago, 2018, Otto Meza, caricaturista: «Soy un mal ateo y un mal cristiano. No estoy seguro si existen los milagros y no estoy seguro de ser 100\% ateo», El Metropolitano Digital, 14.10.2018, https://www.elmetropolitanodigital.com/2018/10/otto-meza-caricaturista-soy-unmal-ateo-y-un-mal-cristiano-no-estoy-seguro-si-existen-los-milagros-y-no-estoy-seg uro-de-ser-100-ateo/ (aufgerufen am 10.8.2020).

Millán Valencia, Alejandro, 2020, Coronavirus: ¿por qué Ecuador tiene el mayor número de contagios y Muertos per cápita de covid-19 en Sudamérica?, BBC News Mundo, 2.4.2020, https://www.bbc.com/mundo/noticias-america-latina-52036460 (aufgerufen am 10.8.2020). 